\title{
Numerical Reconstruction of Hazardous Zones after the Release of Flammable Gases during Industrial Processes
}

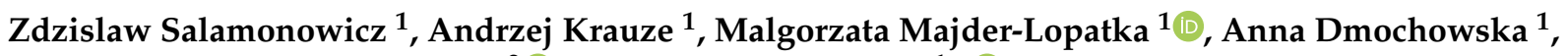 \\ Aleksandra Piechota-Polanczyk ${ }^{2}$ (D) and Andrzej Polanczyk 1,*(D) \\ 1 Faculty of Fire Safety Engineering, The Main School of Fire Service, Słowackiego 52/54 Street, \\ 01-629 Warszawa, Poland; zsalamonowicz@sgsp.edu.pl (Z.S.); akrauze@sgsp.edu.pl (A.K.); \\ mmajder@sgsp.edu.pl (M.M.-L.); admochowska@sgsp.edu.pl (A.D.) \\ 2 Department of Medical Biotechnology, Jagiellonian University, Gronostajowa 7 Street, \\ 30-387 Krakow, Poland; aleksandra.piechota-polanczyk@uj.edu.pl \\ * Correspondence: apolanczyk@sgsp.edu.pl
}

check for updates

Citation: Salamonowicz, Z.; Krauze,

A.; Majder-Lopatka, M.;

Dmochowska, A.;

Piechota-Polanczyk, A.; Polanczyk, A

Numerical Reconstruction of

Hazardous Zones after the Release of

Flammable Gases during Industrial

Processes. Processes 2021, 9, 307.

https: / /doi.org/10.3390/pr9020307

Academic Editors: Gabriella Bognár and Krisztian Hriczo

Received: 20 December 2020

Accepted: 4 February 2021

Published: 6 February 2021

Publisher's Note: MDPI stays neutral with regard to jurisdictional claims in published maps and institutional affiliations.

Copyright: (c) 2021 by the authors. Licensee MDPI, Basel, Switzerland. This article is an open access article distributed under the terms and conditions of the Creative Commons Attribution (CC BY) license (https:/ / creativecommons.org/licenses/by/ $4.0 /)$.

\begin{abstract}
The storage of large numbers of batteries and accumulators is associated with an increased risk of their ignition, which results in the release of significant amounts of hydrogen into the environment. The aim of the study was to reconstruct hazardous zones after hydrogen and liquefied propane-butane (reference gas) release for different industrial processes with the use of numerical methods. Two numerical tools (Fire Dynamics Simulator and Ansys software) were applied for the three-dimensional reconstruction of flammable gas release. Propane-butane was produced from aerosol packages, and hydrogen was produced during battery charging. Emission was analyzed in an industrial building, and both emissions were independent processes. The obtained results indicated that the hazardous zones correspond to the lower explosive level concentrations for both analyzed gasses. Moreover, the high-resolution computational fluid dynamic (CFD) model for flammable gas emissions provided noninvasive and direct quantitative evidence that may influence the safety procedures prepared by regulatory agencies in refining the safety limits in the cost-effective and time-saving manners.
\end{abstract}

Keywords: hydrogen; propane; dispersion; CFD; numerical methods

\section{Introduction}

There are large quantities of hazardous materials in the manufacture, storage, usage and transport industries, which can be accidently discharged from their containers, such as tanks [1]. For several years, an increase in the application of liquefied petroleum gas (LPG) has been observed. Liquefied petroleum gas is flammable and has risks of pool fires during its transportation, storage, and applications [2]. At the same time, hydrogen energy is expanding worldwide; however, safety issues associated with hydrogen use and storage have drawn considerable attention [3,4]. The appearance of an increasing concern related to the releases of industrial hazardous materials (either toxic or flammable) due to terrorist attacks or accidental events in congested industry is observed [5,6]. Moreover, a hazardous gas release can behave like a dense gas because of the low temperature [7], or the presence of aerosols [8].

Air quality models are powerful tools to predict the pollution of gases released into the atmosphere [9]. For gas cloud dispersion, which has a density is greater than ambient air, it is commonly referred to as dense gas or heavy gas [10]. Atmospheric meteorological parameters, such as temperature or humidity, may have significant effects on heavy gas dispersion [11]. There are many general purposes of commercial use of computational fluid dynamic (CFD) software packages capable of modeling and analyzing fluid flows and heat/mass transfer processes useful in industry $[12,13]$. The development of numerical models that are currently used for loss prevention purposes in chemical and process 
industries are associated with three software packages: Phast [14], Aloha [15], and Ansys $[6,15,16]$. CFD simulation method is popular to investigate the properties of different fire scenarios [16,17]. Advanced CFD models of gas release and dispersion have been developed, tested, validated, and applied to the modeling of various industrial real-life indoor and outdoor flammable gases, including hydrogen and methane [12,18]. The group of CFD models includes three subgroups of the following models: RANS (Reynolds-averaged Navier-Stokes equations), LES (large-eddy simulations) and DNS (direct numerical simulation) [19]. Moreover, the characteristics of the atmospheric boundary layer can have an extensive effect on dispersion, because most of the transport, dispersion, and removal of heavy gas occurs inside of an atmospheric boundary layer and, dense gas dispersion usually occurs at the bottom of the atmospheric boundary layer [20]. Therefore, our study aimed to use a CFD technique for the reconstruction of flammable gases emission in the industrial hall. For this purpose, a three-dimensional simulation with the use of Fire Dynamics Simulator (FDS) and Ansys software were prepared. FDS numerically solves an LES form of the Navier-Stokes equations appropriate for low-speed, while ANSYS Fluent uses the RANS subgroup. ANSYS Fluent uses k- $\varepsilon$ turbulence models. The improved turbulent viscosity model, Deardorff (set as default) [21], is implemented in FDS version 6. This model provides a more dynamic flow field range for coarse resolution and tends to the correct result at high resolution. FDS is a Fortran program developed by the National Institute of Standards and Technology (NIST). The CFD simulation enabled the determination of hydrogen and propane, as reference gases, distributed in a closed ventilated hall. Finally, hazardous zones after the emergency release of fire gases in a closed industrial building were prepared.

The paper is organized as follows: in Section 2, materials and methods applied in the research are presented; Section 3 presents the results of computer simulations; in Section 4, a discussion was proposed; finally, Section 5 concludes the paper.

\section{Materials and Methods}

\subsection{Case Study}

This study analyzed an industrial hall (length $=20 \mathrm{~m}$, width $=20 \mathrm{~m}$, height $=6 \mathrm{~m}$ ), in which the release of flammable gases was analyzed (Figure 1). Due to the specificity of firefighters' work, which very often deals with this type of premise, an industrial hall was investigated. The analyzed building was equipped with two ventilation hoods (length $=1 \mathrm{~m}$, width $=1 \mathrm{~m}$, height $=0.05 \mathrm{~m}$ ). One was located in the center of the ceiling. The second ventilation hood was located in the half of one side wall, $0.05 \mathrm{~m}$ above the ground.

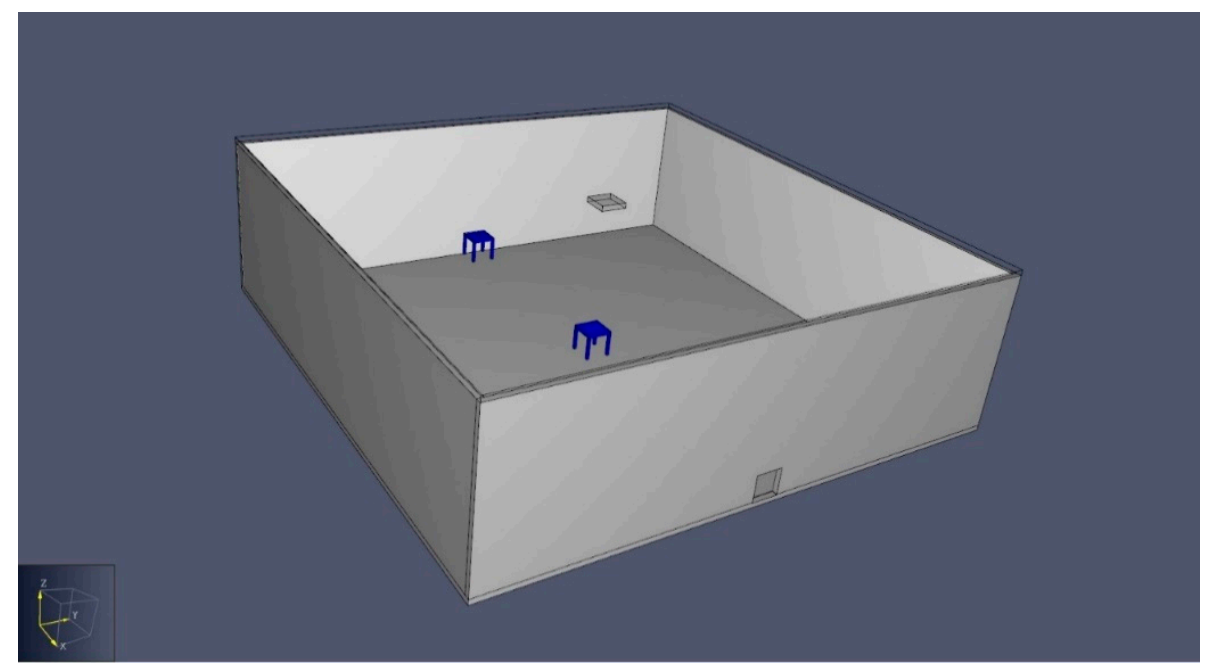

Figure 1. An industrial building where two points of emergency release: blue tables (located on a ground), and two ventilation hoods: dark grey squares (one on a ceiling and one on a wall) were located. 
Each time, for the purpose of the numerical simulations, the emission point $(0.1 \mathrm{~m} \times 0.1 \mathrm{~m})$ was located in the center of table's top surface (Figure 2) in the mathematical domain. Moreover, both tables, both ventilation hoods and both emission points were located on a center line dividing the industrial building in half.

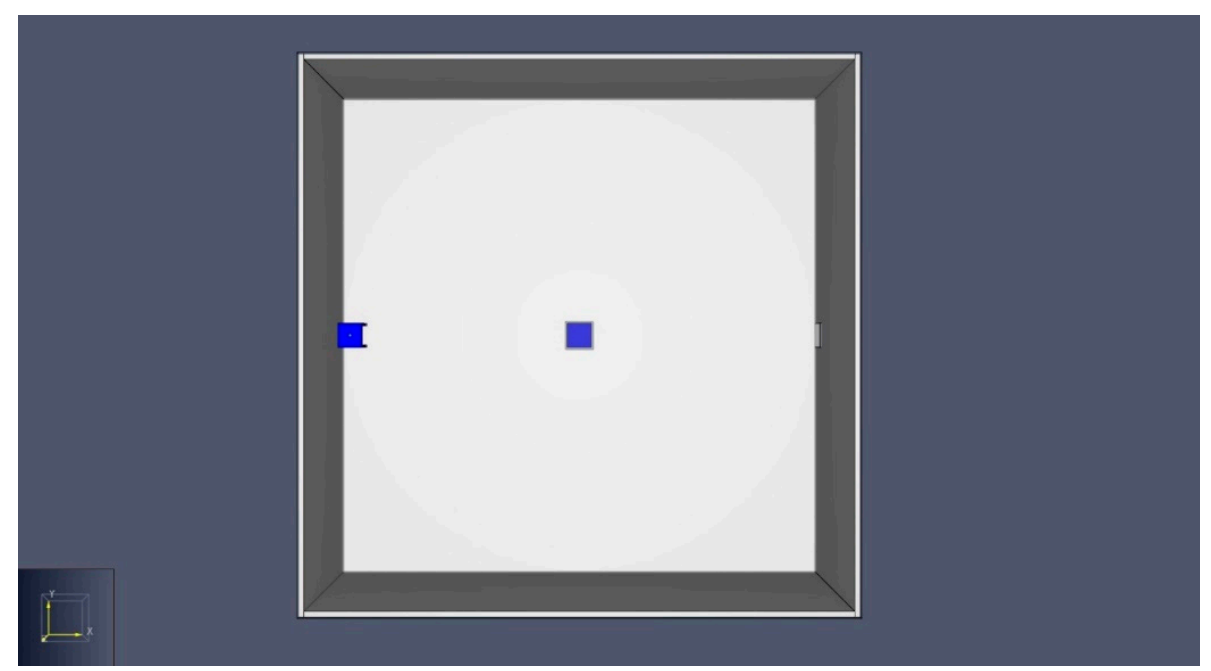

Figure 2. The top view of the analyzed building. Two blue squares represent the emission points.

To reconstruct the flammable gas (hydrogen and propane) release, numerical reconstruction of emergency release included the following steps: (1) production of hydrogen during battery charging when the process of water decomposition into oxygen and hydrogen appeared; (2) emergency release of propane during aerosol production. It was assumed that both processes took place on a dedicated table (blue objects represented on a Figures 1 and 2 ) with equal height $(1 \mathrm{~m})$. The following mass flow rates for the emission of analyzed flammable gases were set: (1) $4.612 \times 10^{-4} \mathrm{~kg} / \mathrm{s}$ for hydrogen; and (2) $6.667 \times 10^{-4} \mathrm{~kg} / \mathrm{s}$ for propane. Emission for hydrogen was calculated with the use of standard EN 50272-2, describing the safety requirements and proper installation of reused stationary batteries. The emission was calculated for a forklift (each forklift had two batteries composed of 72 cells with the capacity of one battery equal to $1300 \mathrm{Ah}$ ). Emission was calculated on the basis of propane emissions from the area of one aerosol package. The emission for propane corresponded to the boiling point from the pool's surface formed after damage of the aerosol's container [22].

\subsection{Numerical Description}

The aim of this study was to determine the range of hazardous zones after an emergency release of flammable gases on the example of hydrogen and LPG. However, the path leading to its achievement consisted of many other tasks. One of the most important was the development of boundary conditions and parameters for numerical calculations. It also defined another goal of the work, which was the confrontation of the results of two applications implementing computational fluid mechanics.

Numerical simulations were performed with the use of two approaches: FDS software and Ansys-Fluent software.

The equations underlying the model implemented in the FDS are presented below.

Mass transport equation (flow continuity equation) (Equation (1)):

$$
\frac{\partial \rho}{\partial t}+\nabla \cdot \rho \mathbf{u}=\dot{m}_{b}^{\prime \prime \prime}
$$

where $\rho$ is the fluid density, $\mathbf{u}$ is the velocity vector, $t$ is the time, and $\dot{m}_{b}^{\prime \prime \prime}$ is the rate of mass appearance associated with evaporation. 
Momentum transport equation (Newton's second law) (Equation (2)):

$$
\frac{\partial}{\partial t}(\rho \mathbf{u})+\nabla \cdot \rho \mathbf{u} \mathbf{u}+\nabla p=\rho \mathbf{g}+\mathbf{f}_{b}+\nabla \cdot \tau
$$

where $p$ is the hydrostatic pressure $\tau$ is the stress tensor, $\mathbf{g}$ is the gravity vector, and $\mathbf{f}_{b}$ is the other external forces.

Enthalpy transport equation (energy balance equation) (Equation (3)):

$$
\frac{\partial}{\partial t}\left(\rho h_{s}\right)+\nabla \cdot \rho h_{s} \boldsymbol{u}=\frac{\partial p}{\partial t}+\boldsymbol{u} \cdot \nabla p+q_{i}
$$

where $h_{s}$ is the specific enthalpy, and $q_{i}$ is the heat exchanged with the environment as a result of chemical reactions, evaporating droplets and through dispersion, as well as heat changes due to conduction and radiation.

Moreover, the following assumptions were additionally made in the algorithm of the FDS software: (1) the fluid was a perfect gas; (2) the fluid was Newtonian (perfectly viscous), which meant that the shear stress in the fluid was directly proportional to the shear rate present in it; (3) heat was conducted according to Fourier's law; and (4) gases diffused according to Fick's laws.

Next, cartesian mesh was prepared. Mesh was divided in two subdomains. One had a higher mesh density, where cubic elements were $0.1 \mathrm{~m}$ in length. This part was $10 \mathrm{~m}$ in length and included a table and two ventilation hoods (yellow rectangle on Figure 3). For the rest of numerical grid, lower density elements $(20 \mathrm{~cm}$ in length) were applied.

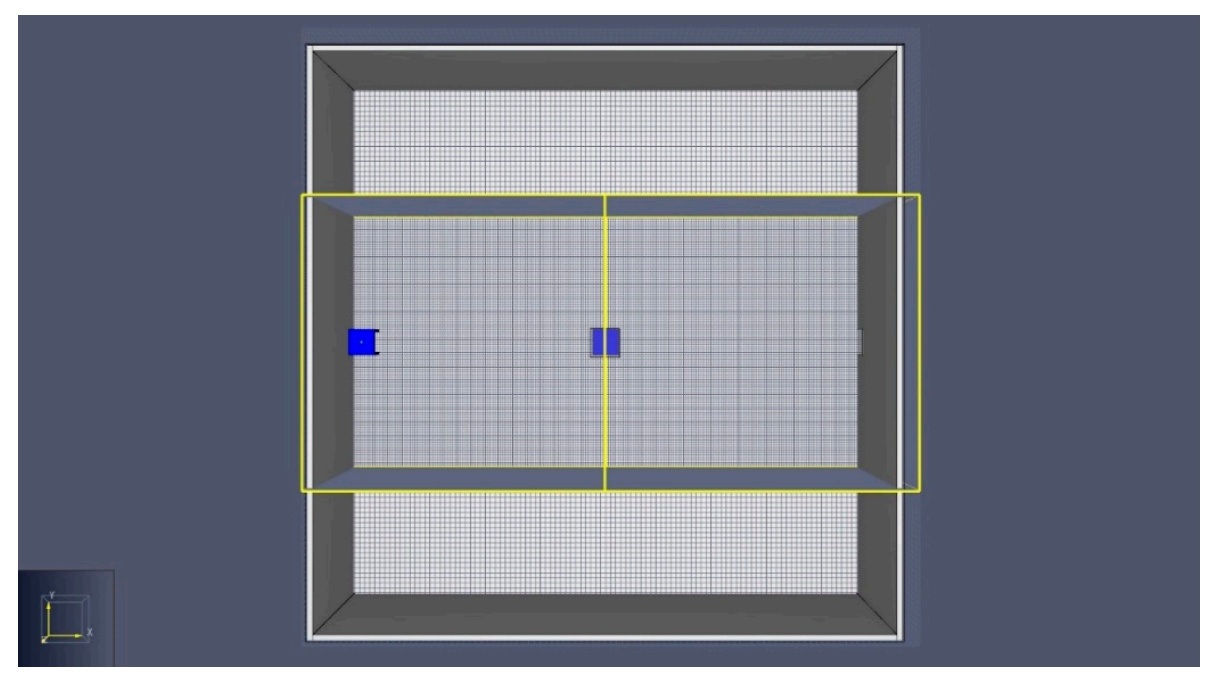

Figure 3. Numerical mesh created in Fire Dynamics Simulator (FDS) with two subdomains. Yellow rectangle indicates the main part of analyzed industrial hall where tables and ventilation hoods were located.

For Ansys software, a similar approach was used. Firstly, a three-dimensional domain was reconstructed with the use of Ansys SpaceClaim software (ANSYS, Canonsburg, PA, USA). In the analyzed domain, four side walls, one ground, and one ceiling were set. Moreover, two emission points located on dedicated tables and two ventilation hoods (one on the ceiling and one on a side wall) were applied. Next, a digital hexagonal grid (with elements $0.01 \mathrm{~m}$ length) with the use of Ansys Meshing software (ANSYS, Canonsburg, PA, USA) with a boundary layer was created. After independent mesh tests, the number of numerical grid elements was established at approximately 2,000,000 for ANSYS Fluent and approximately 1,600,000 elements for FDS software, with the boundary layer composed of five layers. Finally, for the reconstruction of propane and hydrogen emission, AnsysFluent software (ANSYS, Canonsburg, PA, USA) was applied [23,24]. The following boundary conditions were applied: (1) vertical and horizontal partitions were treated as 
wall boundaries, where the derivative of the velocity normal to the surface was zero; (2) vents describing the air movement were described with a constant stream in a direction normal to the surface; and (3) release of analyzed substance was described with a constant stream of a given gas in a direction normal to the surface. For both tables at the top, the mass flow inlet was set.

Continuity (Equation (4)), momentum (Equations (5)-(7)) and energy (Equation (8)) equations for ANSYS Fluent were as follows:

$$
\nabla \cdot \mathrm{u}=0
$$

Reynolds-averaged Navier-Stokes equations (Equations (5)-(7)) were applied [25,26]:

$$
\begin{gathered}
\left(\frac{\partial v_{x}}{\partial t}+v_{x} \frac{\partial v_{x}}{\partial x}+v_{y} \frac{\partial v_{x}}{\partial y}+v_{z} \frac{\partial v_{x}}{\partial z}\right)=\rho g_{x}-\frac{\partial p}{\partial x}+ \\
\frac{\partial}{\partial x}\left(\left(\mu+\mu_{t}\right)\left(2 \frac{\partial v_{x}}{\partial x}\right)\right)+\frac{\partial}{\partial y}\left(\left(\mu+\mu_{t}\right)\left(\frac{\partial v_{z}}{\partial y}+\frac{\partial v_{y}}{\partial x}\right)\right)+\frac{\partial}{\partial z}\left(\left(\mu+\mu_{t}\right)\left(\frac{\partial v_{x}}{\partial z}+\frac{\partial v_{z}}{\partial x}\right)\right) \\
\rho\left(\frac{\partial v_{y}}{\partial t}+v_{x} \frac{\partial v_{y}}{\partial x}+v_{y} \frac{\partial v_{y}}{\partial y}+v_{z} \frac{\partial v_{y}}{\partial z}\right)=\rho g_{y}-\frac{\partial p}{\partial y}+ \\
\frac{\partial}{\partial x}\left(\left(\mu+\mu_{t}\right)\left(\frac{\partial v_{y}}{\partial x}+\frac{\partial v_{x}}{\partial y}\right)\right)+\frac{\partial}{\partial y}\left(\left(\mu+\mu_{t}\right)\left(2 \frac{\partial v_{y}}{\partial y}\right)\right)+\frac{\partial}{\partial z}\left(\left(\mu+\mu_{t}\right)\left(\frac{\partial v_{y}}{\partial z}+\frac{\partial v_{z}}{\partial y}\right)\right) \\
\rho\left(\frac{\partial v_{z}}{\partial t}+v_{x} \frac{\partial v_{z}}{\partial x}+v_{y} \frac{\partial v_{z y}}{\partial y}+v_{z} \frac{\partial v_{z}}{\partial z}\right)=\rho g_{z}-\frac{\partial p}{\partial z}+ \\
\frac{\partial}{\partial x}\left(\left(\mu+\mu_{t}\right)\left(\frac{\partial v_{z}}{\partial x}+\frac{\partial v_{x}}{\partial z}\right)\right)+\frac{\partial}{\partial y}\left(\left(\mu+\mu_{t}\right)\left(\frac{\partial v_{z}}{\partial y}+\frac{\partial v_{y}}{\partial z}\right)\right)+\frac{\partial}{\partial z}\left(\left(\mu+\mu_{t}\right)\left(\frac{\partial v_{z}}{\partial z}\right)\right) \\
\frac{\partial}{\partial x}(\rho h)+\nabla \cdot(\vec{v} \rho h)=\nabla \cdot(k \nabla T)+S_{h}
\end{gathered}
$$

where $v_{x}, v_{y}, v_{z}$ are the velocity components for $x, y, z$ directions $(\mathrm{m} / \mathrm{s}) ; t$ is the time (s); $g$ is the acceleration in the $x, y, z$ directions $\left(\mathrm{m}^{2} / \mathrm{s}\right) ; \mu$ is the fluid viscosity (Pa.s); $\rho$ is the fluid density $\left(\mathrm{kg} / \mathrm{m}^{3}\right) ; \mu_{t}$ is the turbulent viscosity $(\mathrm{Pa} \cdot \mathrm{s}) ; h$ is the enthalpy; $k$ is the conductivity; $T$ is the temperature; and $S_{h}$ is the heat source.

In this work, the $k-\varepsilon$ model was used to represent the effects of turbulence [27].

Results were presented as iso-surfaces with lower explosive level (LEL) values assigned. In the first step, stationary results for particular LEL values in FDS were presented. For Ansys-Fluent software, the RANS model was applied. Next, transient results illustrated the flammable gas concentration distribution as a function of time.

\section{Results}

Numerical reconstruction of dispersion process enabled the analysis of two flammable gas emissions. Two substances were analyzed, propane and hydrogen.

\subsection{Propane Dispersion}

In order to illustrate the distribution of propane as a gas heavier then air, an isosurface with a concentration of 5\% LEL was presented. For these conditions, propane flowed towards the floor and spread throughout the room (Figure 4).

ANSYS software analysis of propane concentration distribution corresponding to $25 \%$ LEL indicated that it was directed into one side of the analyzed building (Figure 5a). After reaching the level of the floor, propane began to spread across the surface. Furthermore, the concentration of propane was within a radius of about $2.5 \mathrm{~m}$ from the center of the release source. The FDS software indicated a uniform distribution of propane, shaped around the table (Figure 5b). 


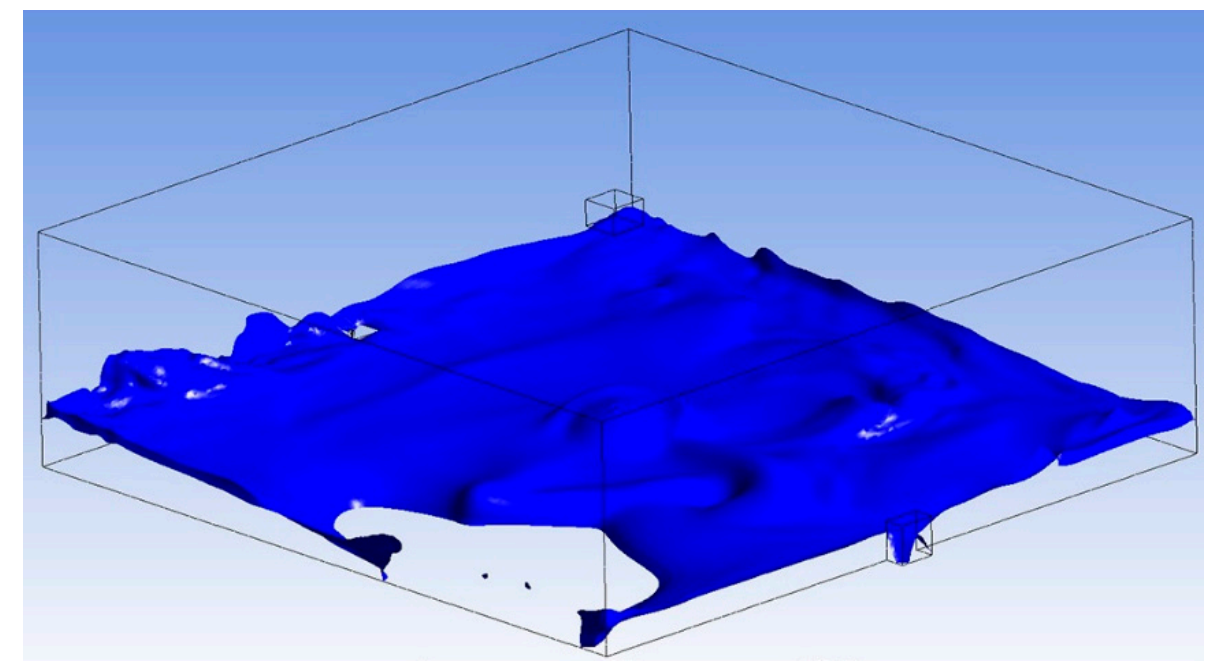

Figure 4. Iso-surface for propane representing $5 \%$ concentration of the lower explosive level (LEL).

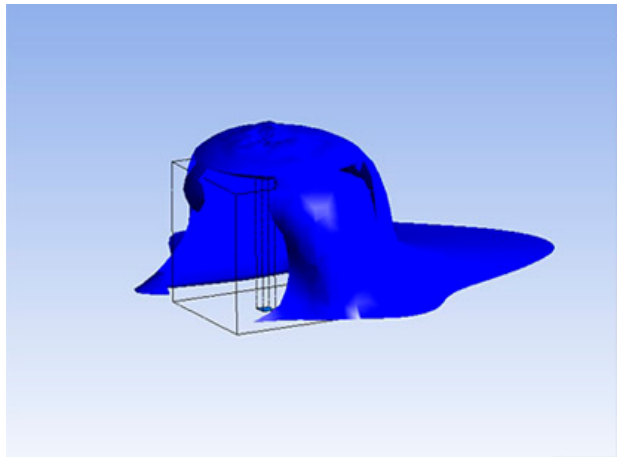

(a)

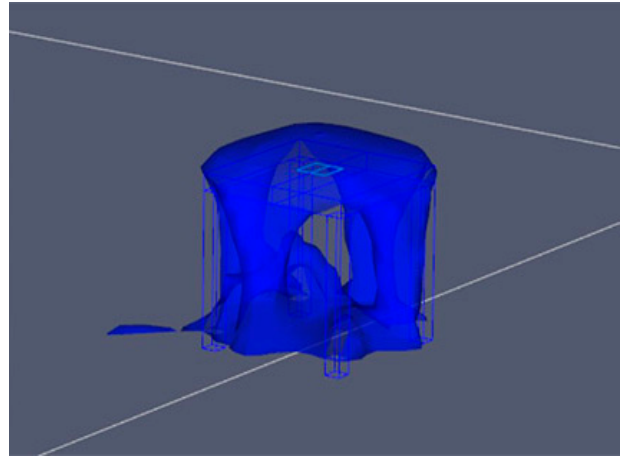

(b)

Figure 5. Iso-surface for propane representing 25\% concentration of LEL for (a) Ansys software and (b) FDS.

The iso-surfaces describing the concentration corresponding to 50\% LEL are characterized in Figure 6. In the ANSYS software, propane dispersion was directed to one side and spread more intensively in one direction, falling towards the floor (Figure 6a). In the FDS program, the concentration distribution was quite uniform, and filled the entire surface of the countertop (Figure 6b).

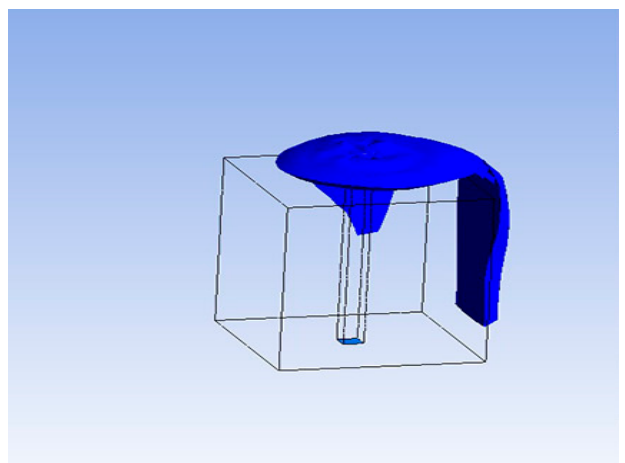

(a)

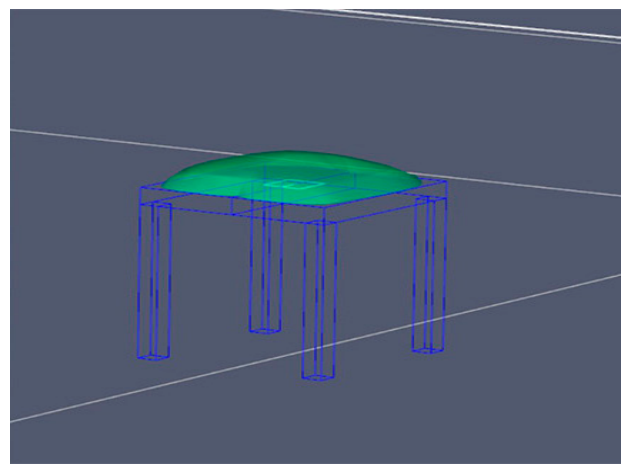

(b)

Figure 6. Iso-surface for propane representing 50\% concentration of LEL for (a) Ansys software and (b) FDS. 
Moreover, the dispersion of propane as a function of time was analyzed. Due to the spatial configuration of the table from which gas was released, and the properties of propane, numerical simulations included the time it took for propane to flow from the ground level to the surface of a table, where the concentration of propane was equal to $25 \%$ of the LEL. It lasted approximately $10 \mathrm{~s}$ in Ansys software. To achieve the above conditions in Ansys software, it took $20 \mathrm{~s}$ (Figure 7a), while in FDS it lasted only $10 \mathrm{~s}$ (Figure $7 \mathrm{~b}$ ). Therefore, in further analysis a $10 \mathrm{~s}$ shift between the results from Ansys software and FDS appeared. Gas was continuously emitted during the first $10 \mathrm{~s}$. This would have resulted in more gas being released overall in the computational domain; thus, lower concentrations around the table could have been reached faster. This was an acceptable circumstance because the main purpose of the comparisons was to confront higher concentrations. Moreover, the concentration at the level of 5\% LEL was measured, located on the central axis of the table. Such a small value allowed the spread of the substance to be accurately observed.

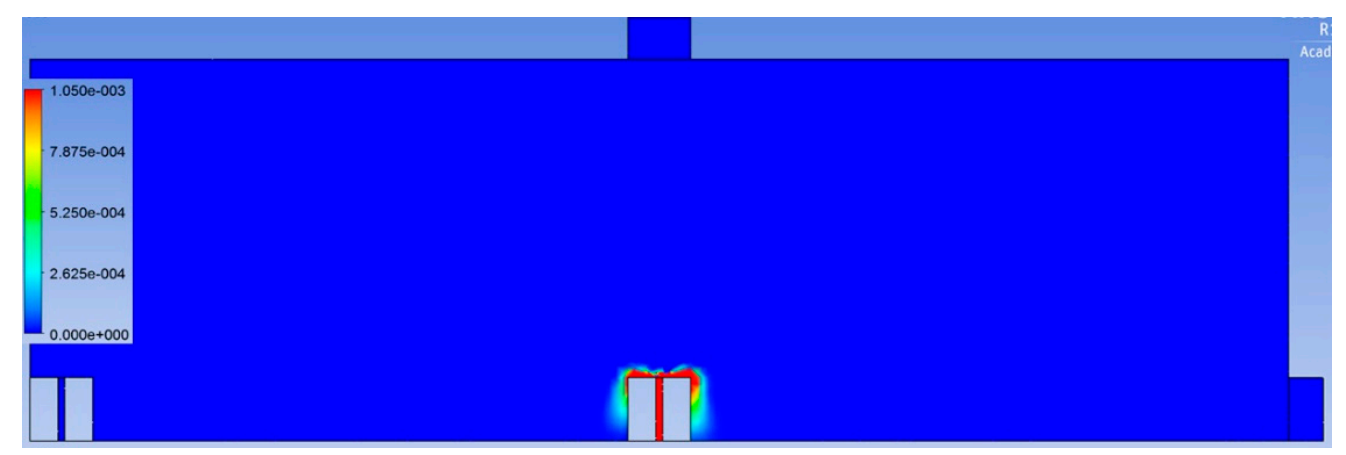

(a)

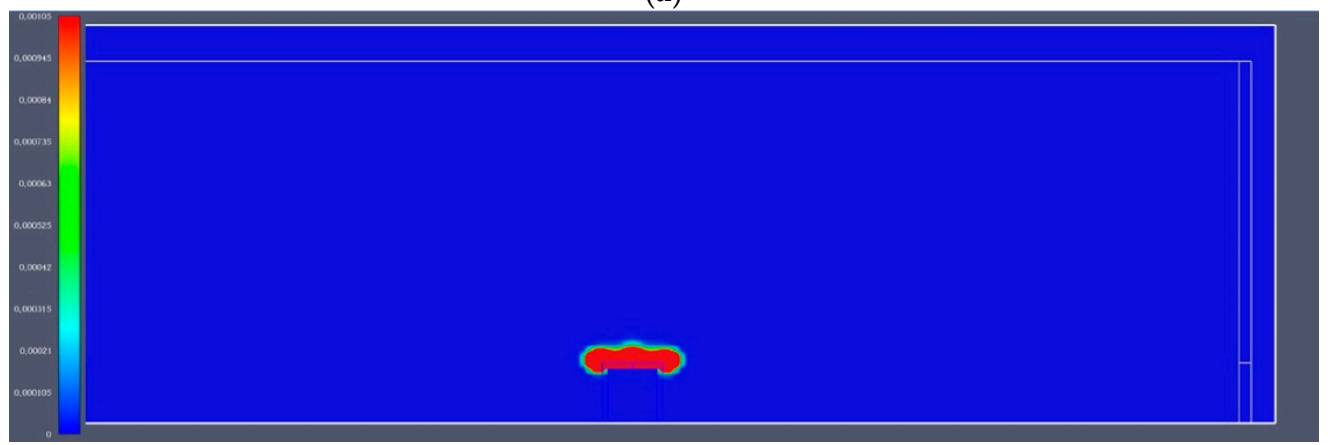

(b)

Figure 7. Comparison of propane dispersion for $5 \%$ concentration of LEL for time $10 \mathrm{~s}$ : (a) propane release calculated with Ansys software; (b) propane release calculated with FDS software.

In Ansys software, it was observed that after 25 s propane was directed vertically downwards and only after reaching the floor level did it move in the parallel direction (Figure 8a). However, in FDS software, propane was moved downwards and horizontally after leaving the top surface of the table (Figure $8 b$ ).

After $50 \mathrm{~s}$, propane was observed across the floor surface within a radius of about $3 \mathrm{~m}$ from the source of the release (Figure 9).

In the hundredth second of the simulation, propane had already filled the majority of the floor area. This situation is shown in Figure 10. It should be noted that the concentration corresponding to 5\% LEL in the ANSYS program was present only within a radius of about $1.5 \mathrm{~m}$ from the source of the release. At further distances, the propane concentration was lower. These conditions did not occur in the FDS program, in which the desired concentration occurred almost in the entire area filled with propane (Figure 11). 


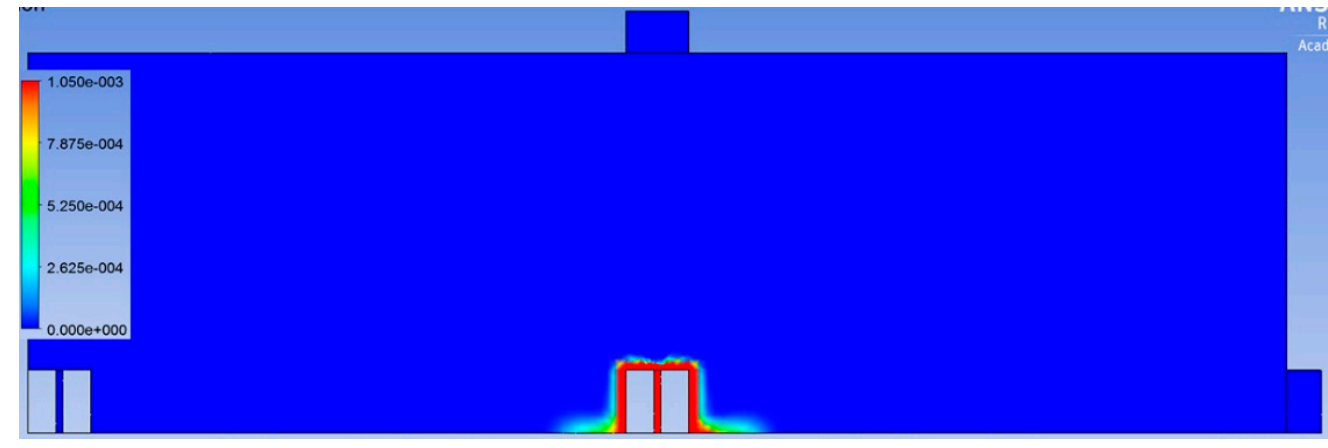

(a)

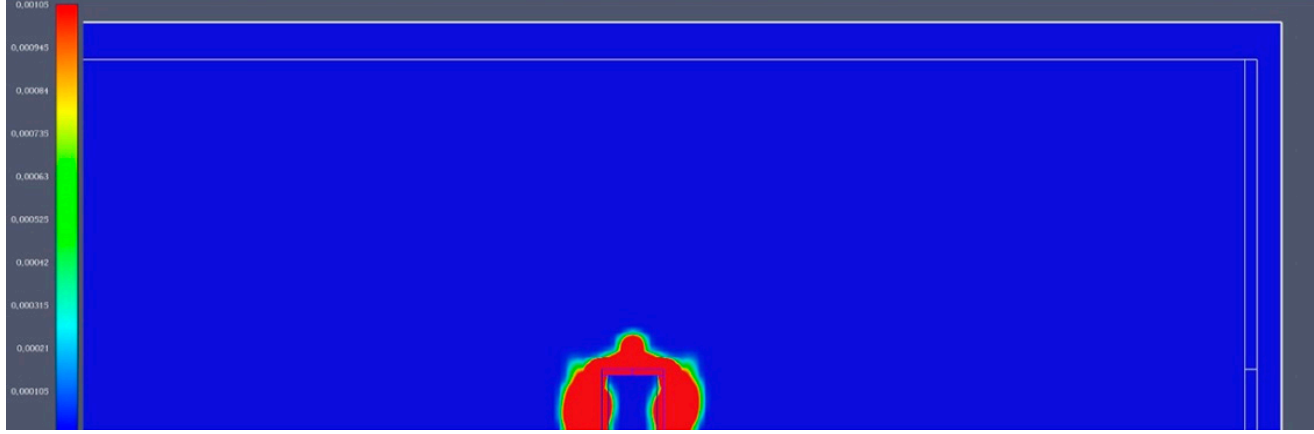

(b)

Figure 8. Comparison of propane dispersion for $5 \%$ concentration of LEL for time 25 s: (a) propane release calculated with Ansys software; (b) propane release calculated with FDS software.

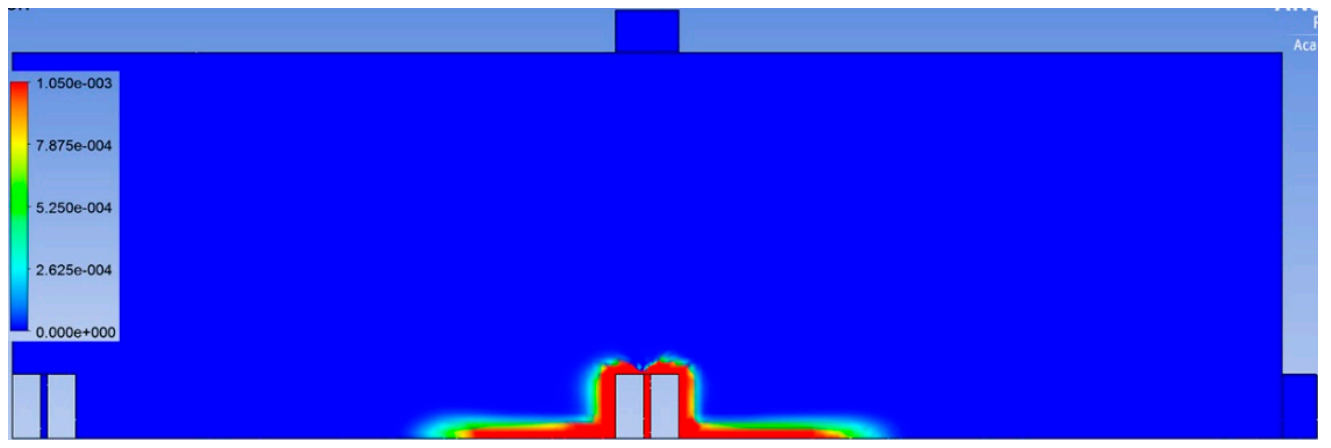

(a)

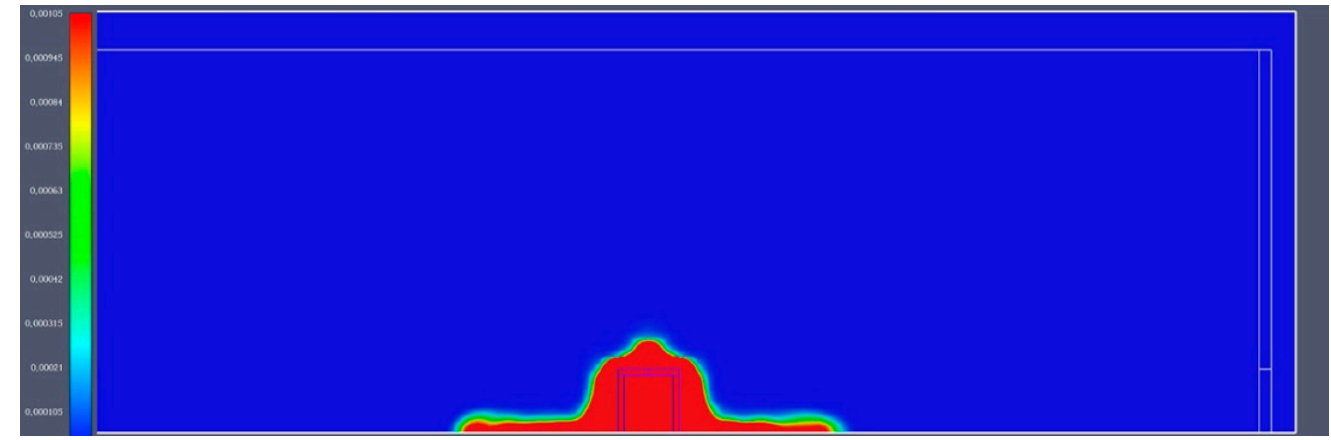

(b)

Figure 9. Comparison of propane dispersion for $5 \%$ concentration of LEL for time 50 s: (a) propane release calculated with Ansys software; (b) propane release calculated with FDS software. 


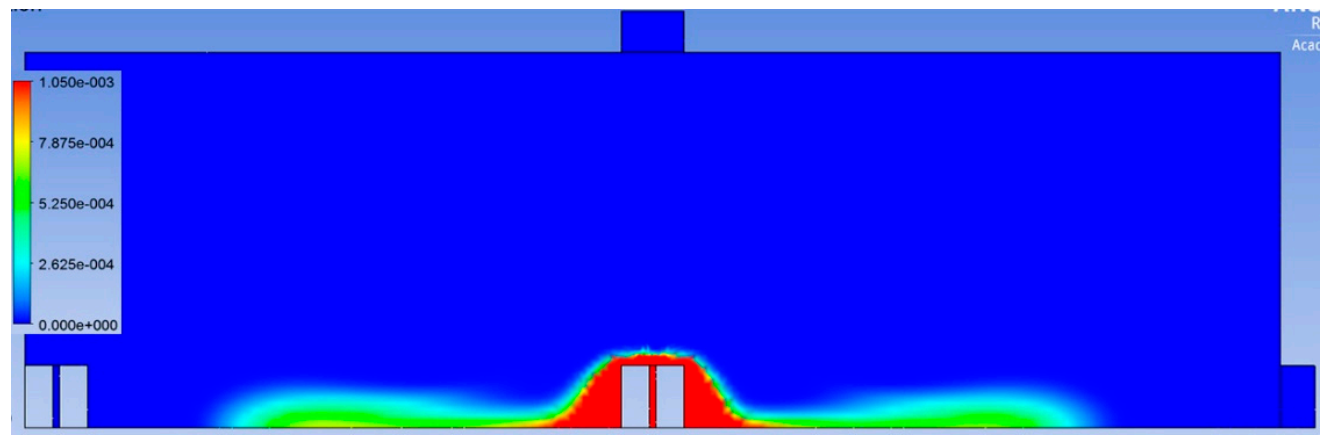

(a)

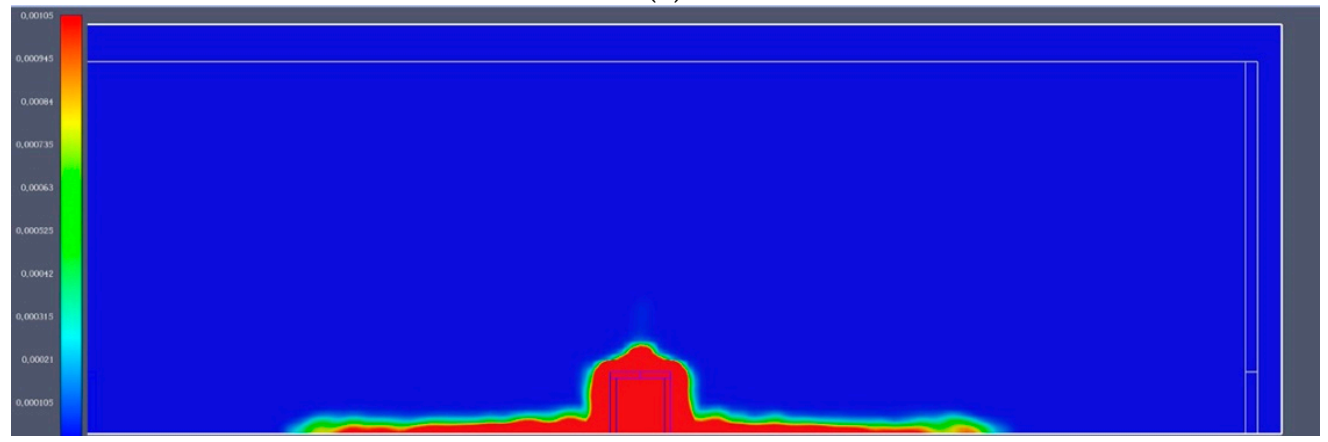

(b)

Figure 10. Comparison of propane dispersion for $5 \%$ concentration of LEL for time 100 s: (a) propane release calculated with Ansys software; (b) propane release calculated with FDS software.

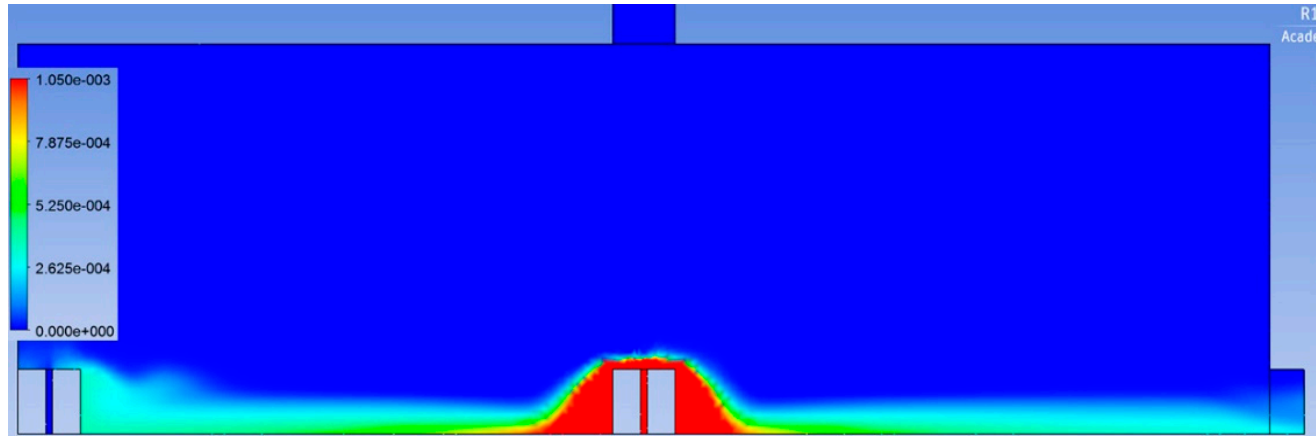

(a)

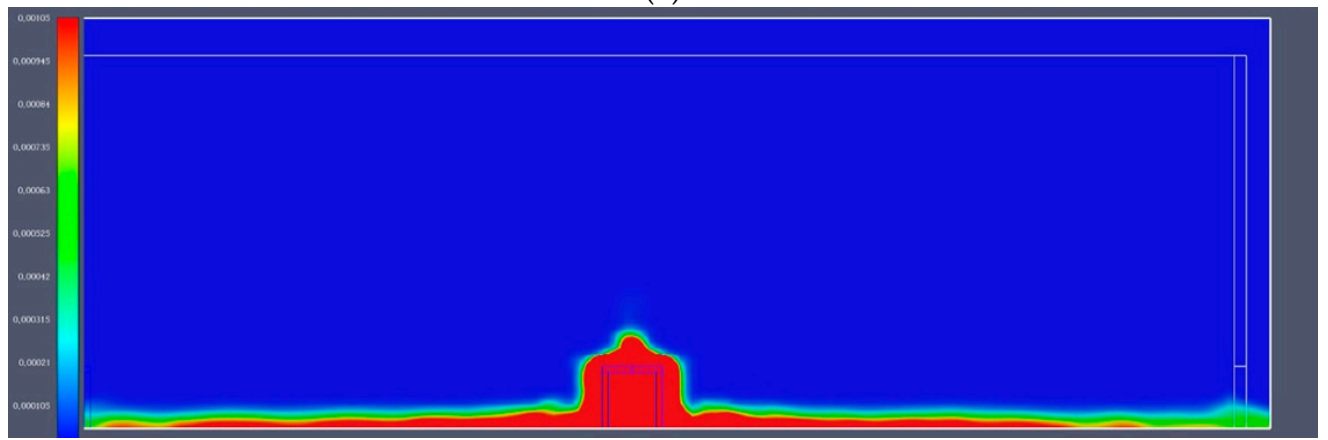

(b)

Figure 11. Comparison of propane dispersion for $5 \%$ concentration of LEL for time $250 \mathrm{~s}$ : (a) propane release calculated with Ansys software; (b) propane release calculated with FDS software.

\subsection{Hydrogen Dispersion}

Results from FDS software for $25 \%$ of hydrogen LEL indicated that gas was concentrated near the source of the emission at a height equal to $30 \mathrm{~cm}$ (Figure 12). There was a 
high agreement between the results from FDS and Ansys software. For both approaches, a similar shape and high of dispersion was observed.

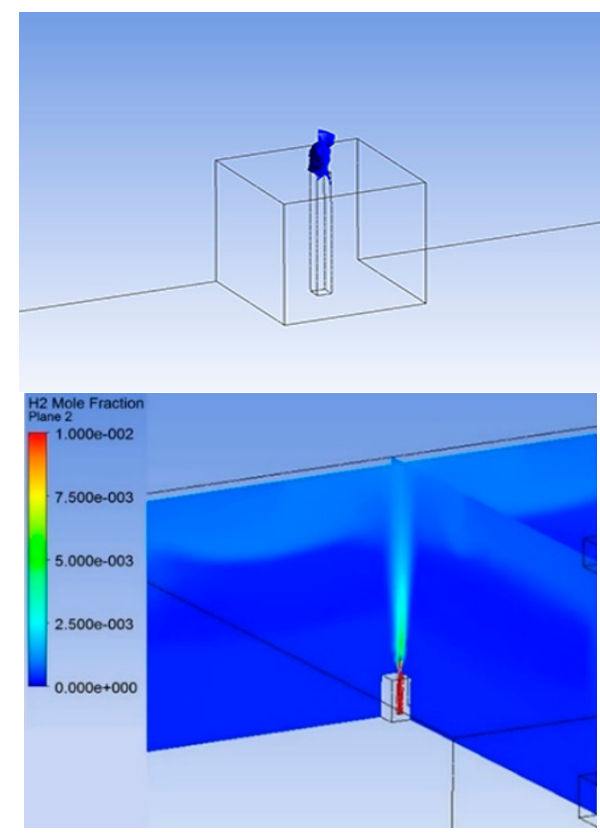

(a)

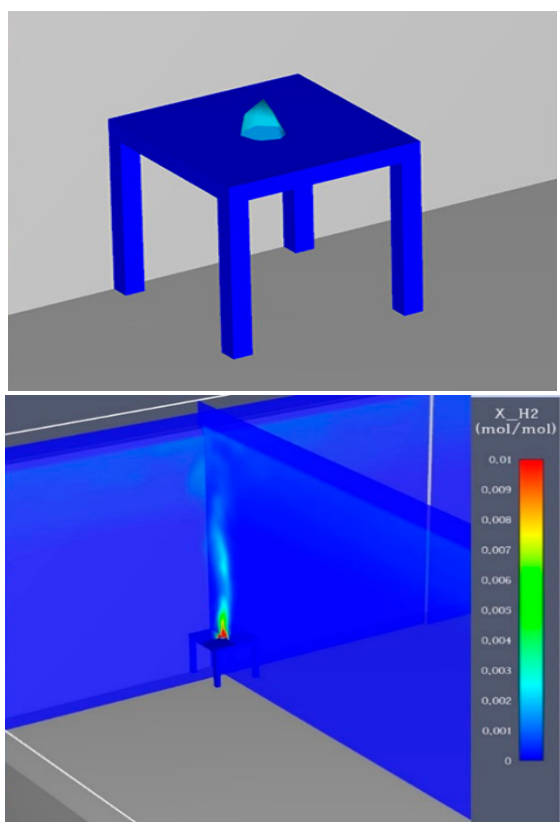

(b)

Figure 12. Iso-surface for hydrogen representing $25 \%$ concentration of LEL for (a) Ansys software and (b) FDS.

The iso-surface representing the $50 \%$ of LEL concentration for hydrogen in the FDS software appeared only around the source of the emission (Figure 13b). The results from Ansys software appeared in the same place, however reached a higher level (approximately $0.2 \mathrm{~m}$ ) (Figure 13a).
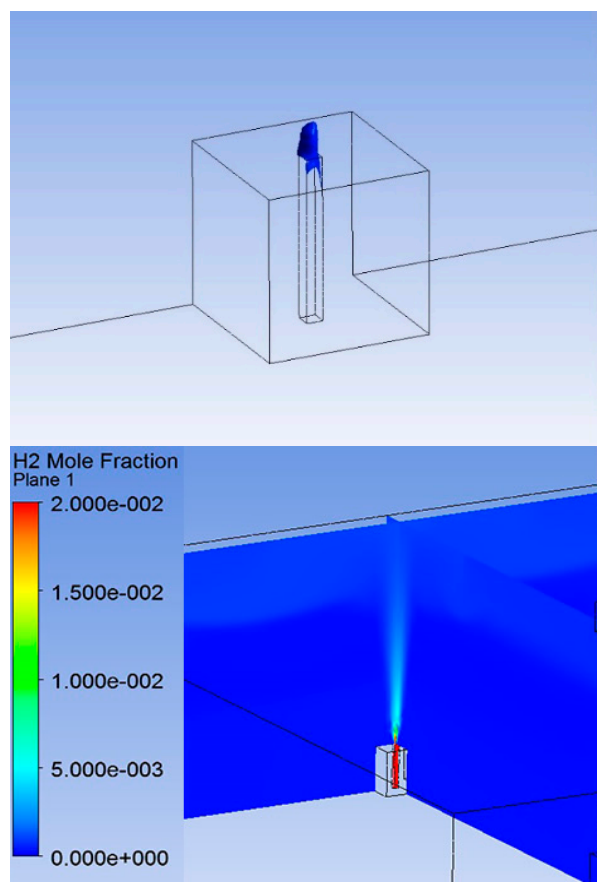

(a)

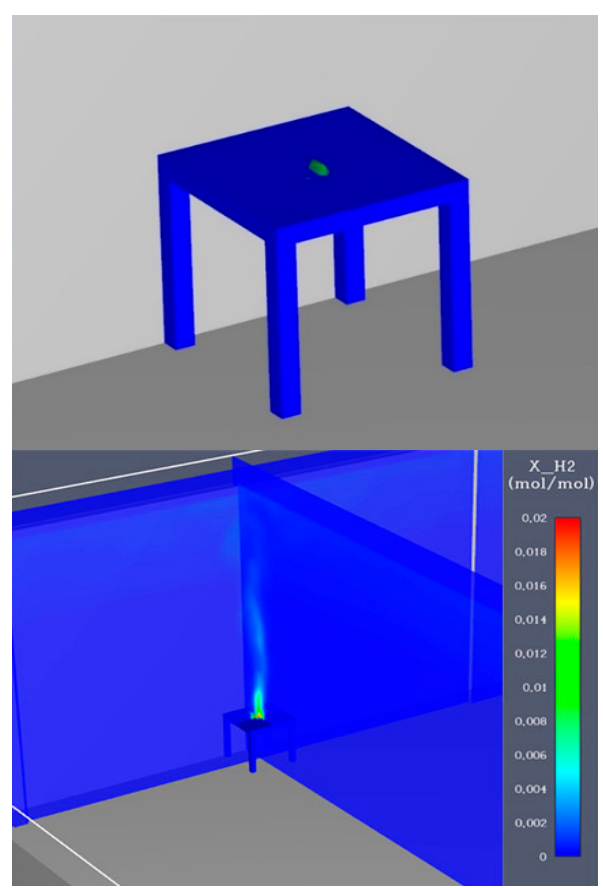

(b)

Figure 13. Iso-surface for hydrogen representing 50\% concentration of LEL for (a) Ansys software and (b) FDS. 
In order to illustrate the differences in the rate of hydrogen propagation, a comparison of the gas concentration as a function of time for $1.5 \%$ of LEL was performed. It was observed that hydrogen distribution after $10 \mathrm{~s}$ presented a similar height of released gas for both approaches (FDS and Ansys software). However, distribution of hydrogen concentration in Ansys software indicated a wider area of gas comparing to FDS software. For Ansys software, it was equal (approximately 1 m; Figure 14a), while for FDS software it was approximately $10 \mathrm{~cm}$ (Figure 14b).

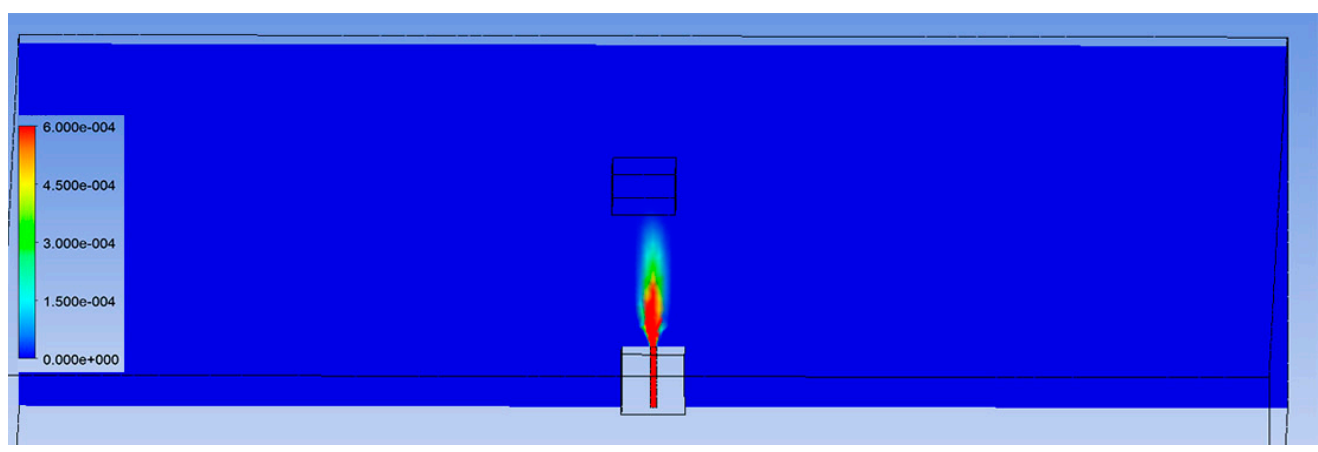

(a)

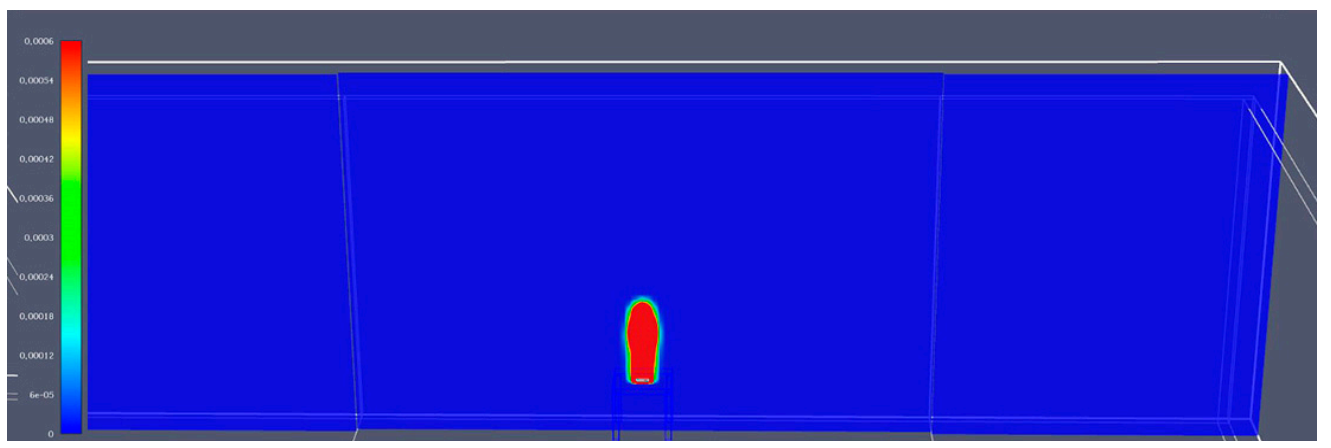

(b)

Figure 14. Comparison of hydrogen dispersion for $1.5 \%$ concentration of LEL for time $10 \mathrm{~s}$ : (a) propane release calculated with Ansys software; (b) propane release calculated with FDS software.

Analysis of hydrogen distribution after $25 \mathrm{~s}$ indicated that the 1.5\% LEL area was approximately $3 \mathrm{~m}$ above the table. As previously presented, Ansys software (Figure 15a) indicated a much larger lower concentration area compare to FDS software (Figure 15b).

After $50 \mathrm{~s}$, hydrogen reached the ceiling level and spread parallelly. It was observed that FDS software simulated more hydrogen near the ceiling with higher concentration (Figure 16b). The results from Ansys software indicated no appearance of hydrogen at the level of 1.5\% LEL (Figure 16a). In the FDS software, it was presented in the area of approximately $1 \mathrm{~m}$ radius.

Results after $100 \mathrm{~s}$ indicated that hydrogen occurred below the ceiling in the area equal to approximately $10 \mathrm{~m}$ for both FDS and Ansys software (Figure 17).

After $250 \mathrm{~s}$, hydrogen was presented below the entire ceiling zone. However, similarly to the previous time step, the concentration of $1.5 \%$ LEL hydrogen was presented only in the center axis of the table from which emission had started (Figure 18). 


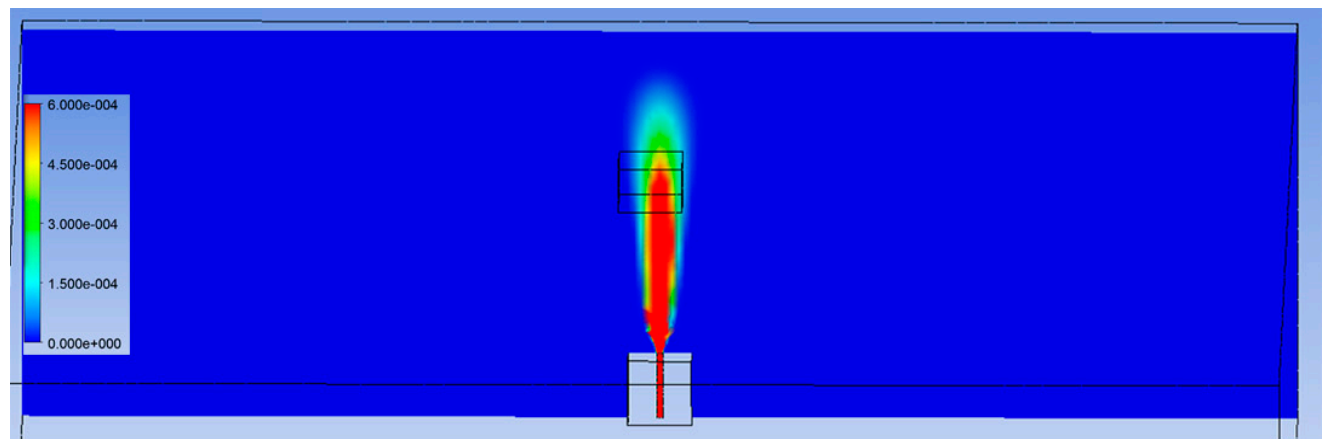

(a)

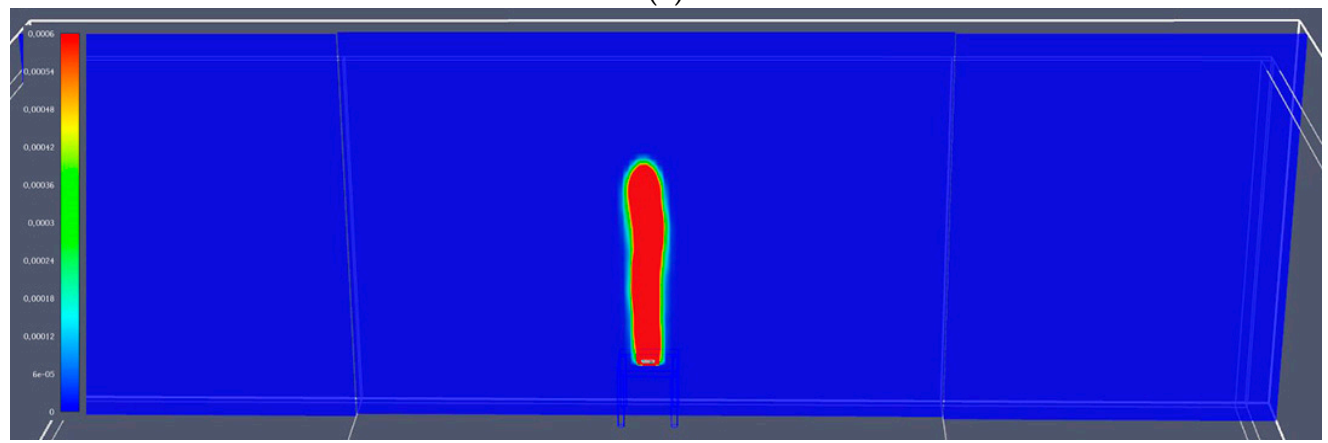

(b)

Figure 15. Comparison of hydrogen dispersion for $1.5 \%$ concentration of LEL for time $25 \mathrm{~s}$ : (a) propane release calculated with Ansys software; (b) propane release calculated with FDS software.

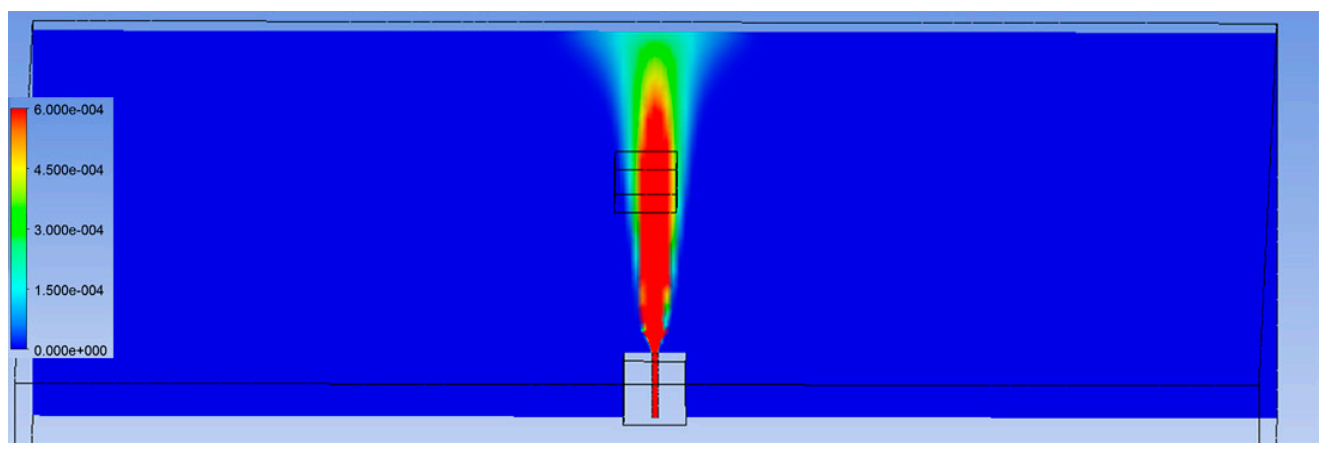

(a)

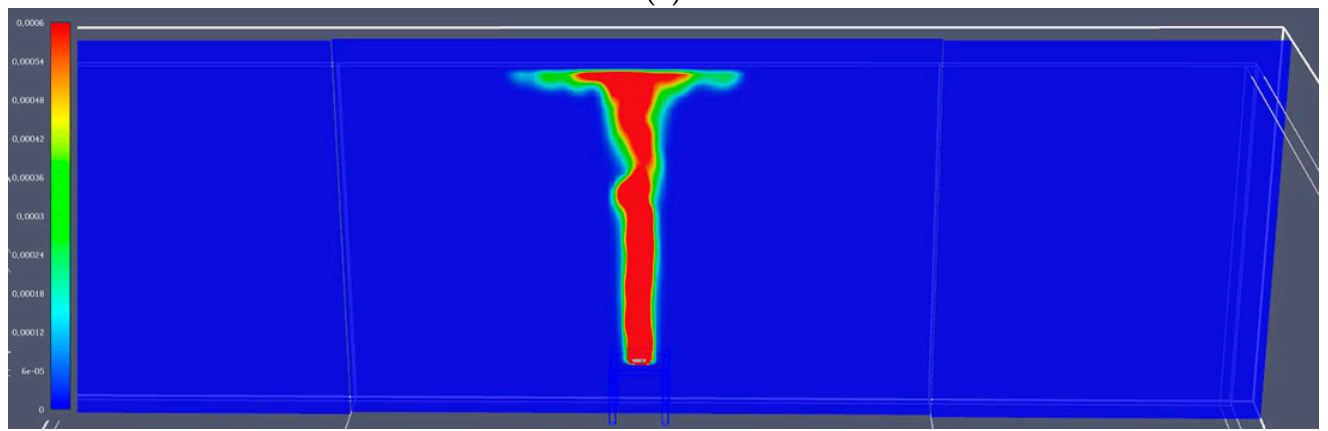

(b)

Figure 16. Comparison of hydrogen dispersion for $1.5 \%$ concentration of LEL for time $50 \mathrm{~s}$ : (a) propane release calculated with Ansys software; (b) propane release calculated with FDS software. 


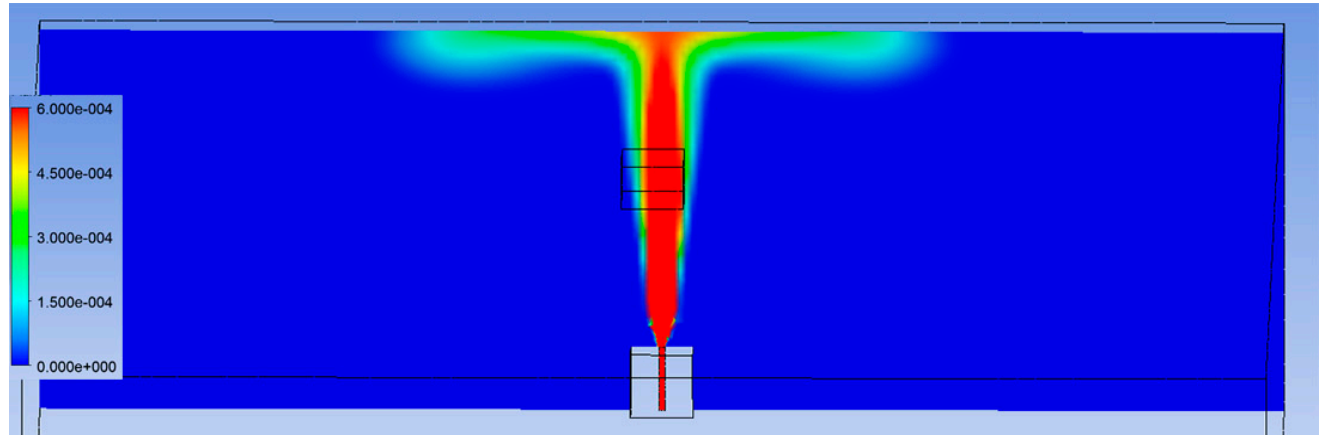

(a)

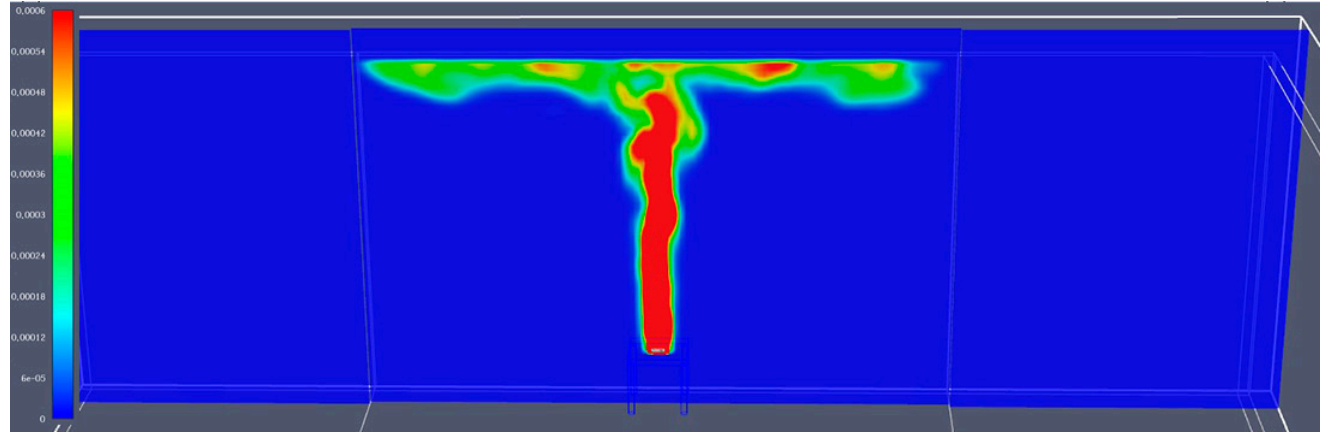

(b)

Figure 17. Comparison of hydrogen dispersion for $1.5 \%$ concentration of LEL for time $100 \mathrm{~s}$ : (a) propane release calculated with Ansys software; (b) propane release calculated with FDS software.

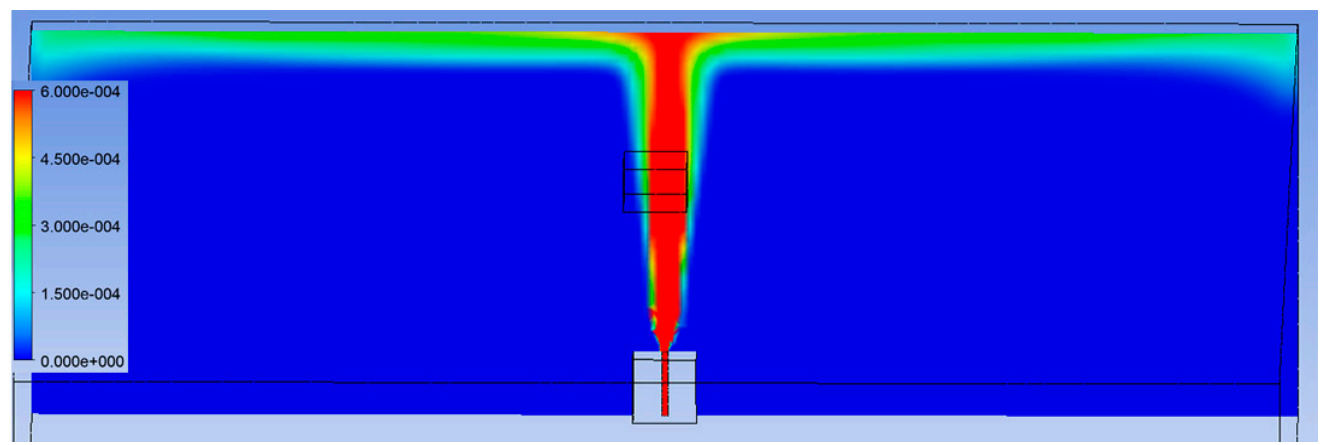

(a)

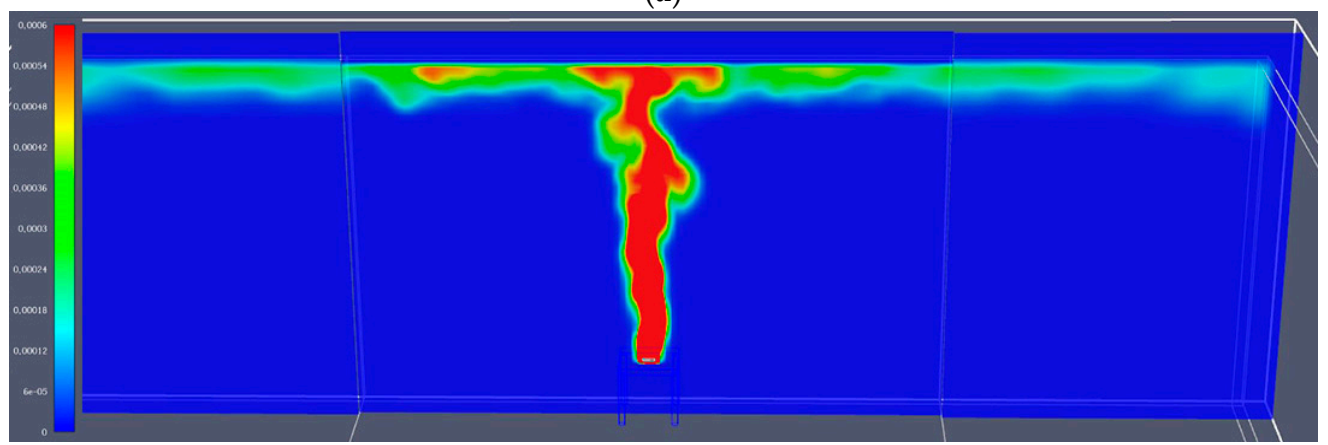

(b)

Figure 18. Comparison of hydrogen dispersion for 1.5\% concentration of LEL for time $250 \mathrm{~s}$ : (a) propane release calculated with Ansys software; (b) propane release calculated with FDS software.

\section{Discussion}

The usually applied size for the hazardous zones for forklift battery charging stations cover the area within $0.5 \mathrm{~m}$ from the battery pack and up to the ceiling [28]. The presented results indicate that the size of the hazardous zone is much smaller; the concentration 
corresponding to the LEL of hydrogen is located in the area located directly above the source of release (about $0.2 \mathrm{~m}$ ). In the case of aerosol production, the following explosion hazard zones are designated: zone 0 -in a container; zone 1 - at a distance of $1 \mathrm{~m}$; zone 2 -from the border of zone 1 at a distance of $1 \mathrm{~m}$ to the floor. It was observed that concentrations within the explosive limits occurred only within a radius of about $0.25 \mathrm{~m}$ at a height of up to $0.2 \mathrm{~m}$ from the emission source.

The methodology presented in this study provides a mathematical tool to assess whether the emission of flammable gases in an industrial hall to a given fire scenario can be deemed safe. The analysis of the case studies enabled quantifying of the effect of different gases and geometrical conditions on the emergency release.

With the use of iso-surfaces, it was possible to present the existence of LEL values in the analyzed industrial hall. It was in line with Scarponi et al. who, with the use of pressurization curves and temperature maps obtained from CFD calculations, performed stress analysis for predicting if and when a vessel would fail [29]. Moreover, Bi et al. analyzed turbulent flow with the use of a standard k- $\varepsilon$ model, which was in line with the approach presented in our paper [30].

Analysis of hydrogen distribution for the emission process indicated that hydrogen was present at the upper part of the industrial hall. Contrary to our results, Hwang et al. observed horizontal cloud transport at low height [31]. Similarly, Rigas and Sklavounos who indicated that a spreading hydrogen cloud is similar to that of liquefied natural gas [32].

The main factor influencing the difference in modeling results is the use of different turbulence models. The LES model allows for a detailed reflection of the processes of turbulent mixing of gases with air and, unlike the RANS models (e.g., k-epsilon) which use values averaged over time, more precise determination of instantaneous concentrations of substances. Additionally, the assumptions of the research space geometry have an influence on small differences in the results. In Ansys Fluent, the inlet of the gas emitter takes place through a channel that allows stabilization of the flow, while in the FDS, the gas emission is realized directly as emission is perpendicular to the selected surface.

Moreover, the main problem in outdoor simulations is the modeling of atmospheric turbulence for various classes of atmospheric stability. However, for the most stable atmosphere where there is almost no turbulence (class F), which is also the most dangerous due to the farthest ranges of clouds, modeling without taking into account turbulence provides good results. This problem does not occur indoors. Krauze conducted a series of experiments aimed at checking the suitability of FDS in modeling the spread of gases and vapors in closed spaces as well as in open spaces; the spread of methane, propane and gasoline vapors was investigated. The results were satisfactory for methane and gasoline, while for propane the concentrations were slightly higher than the real ones [33].

\section{Limitations to the Study}

The CFD model was used within one industrial building, and only two gases (propane and hydrogen) were analyzed. Emissions were reconstructed from one type of flat surface. In the future, we would like to analyze different spatial configurations of emission surfaces. Moreover, we analyzed the process under constant temperature. In the future, we would like to include different environmental temperatures, which may reflect different seasons.

\section{Conclusions}

The purpose of this study was to designate hazardous zones after the emergency release of flammable gases (LPG and hydrogen). Currently, liquefied propane-butane gas is widely used on a global scale, while intensive work is being undertaken with hydrogen to implement it as the fuel of the future. Therefore, one should be aware of the existence and size of hazardous zones created by them. In order to determine the searched areas, the ANSYS and FDS software using computational fluid mechanics were applied. For the purposes of this study, a total of several dozen simulations were made. Most of them were not configured well enough, which forced the application of corrections and restarting the 
calculations. During the analysis of the results, eight final simulations were used, which included corrections of all previously committed errors. Six of them were made for the ANSYS software, and two for the FDS software. The maximum available time in the FDS was considered as the final simulation time. The observation in ANSYS software was adjusted to this value.

It was observed that, for the adopted mesh resolution, the results from FDS software presented a lower accuracy of mapping the outflow next to the point of the factor release, compared to the simulation performed in the Fluent software. However, further from the source of the emission, the flow of the released substance was more precisely mapped than in the Fluent software. This was due to the more accurate modeling of turbulence using the LES method implemented in the FDS software, compared to the RANS method used in the Fluent software.

It was observed that hydrogen, as a lighter gas than air, concentrated on the top of the analyzed building, under the ceiling. The concentration corresponding to the LEL of hydrogen was achieved only in the ANSYS software, and it covered a cubic shape (length $10 \mathrm{~cm}$ ). A concentration of 50\% LEL of hydrogen occurred above the emission source and reached a height of about $20 \mathrm{~cm}$, while the concentration of $25 \%$ LEL reached a height of about $30 \mathrm{~cm}$ and was located directly above the source.

For propane gas, the concentration of $25 \%$ of LEL in the FDS software was distributed evenly around the axis of the table; ANSYS software directed the spread in one direction, in which this concentration was visible even at a distance of $2.5 \mathrm{~m}$ from the source of the emission. For $50 \%$ of LEL concentration, propane was directly above the tabletop. Moreover, in the case of ANSYS software, there was an area outside the table, directed towards the ground. Furthermore, for propane, the following explosion hazard zones were designated: zone 0 -in the container; zone 1 -at a distance of $1 \mathrm{~m}$; zone 2-from the border of zone 1 at a distance of $1 \mathrm{~m}$ from the floor. Analyzing the simulation results, it can be concluded that, as in the case of hydrogen, the zone sizes were overestimated. Concentrations within the explosive limits occurred only within a radius of about $25 \mathrm{~cm}$ at a height of up to $20 \mathrm{~cm}$ from the emission source.

Moreover, the high-resolution CFD model for flammable gas emissions provided noninvasive and direct quantitative evidence to enhance the fundamental understanding on the safety procedures, which can assist regulatory agencies in refining the safety limits in the cost-effective and time-saving manners.

In conclusion, it should be noted that the release values adopted in this study resulted in the formation of hazardous zones with a value corresponding to the concentration of the lower explosive level. In addition, the predictable behavior of lighter- and heavier-than-air gases, which rose to the ceiling or fell towards the ground, respectively, was confirmed. Moreover, on the basis of the analysis of the results, the compliance of two software packages implementing CFD techniques was found. Computational fluid mechanics offers great opportunities to simulate phenomena governed by the laws of fluid motion. As never before, we are faced with the possibility of conducting very accurate and relatively fast processes, leading to reliable results being obtained. The operation of the software is relatively simple; therefore, every production plant or other place where the release of hazardous gases is possible should apply the simulation.

Author Contributions: Conceptualization, Z.S. and A.K.; methodology, Z.S.; software, Z.S., A.K., A.P.; validation, A.P.-P., M.M.-L., and A.D.; formal analysis, A.P. and A.P.-P.; investigation, Z.S.; resources, Z.S.; data curation, A.K. and A.P.; writing—original draft preparation, A.P., A.K. and A.D.; writing-review and editing, A.P.-P. and Z.S.; visualization, Z.S.; supervision, Z.S. and A.P.; project administration, Z.S.; funding acquisition, Z.S. All authors have read and agreed to the published version of the manuscript.

Funding: This research received no external funding.

Institutional Review Board Statement: Not applicable.

Informed Consent Statement: Not applicable. 
Data Availability Statement: The data used to support the findings of this study are available from the corresponding author upon request.

Conflicts of Interest: The authors declare no conflict of interest.

\section{References}

1. Juanxia, H.; Lei, L.; Angang, L.; Ye, M.; Dongmei, Z.; Qiyong, Z.; Yongzhong, Z. A dense gas dispersion model based on revised meteorological parameters and its performance evaluation. Atmos. Environ. 2021, 244, 12.

2. Hang, Y.; Feng, Y.; Wang, Q. Computational fluid dynamics (CFD) study of heat radiation from large liquefied petroleum gas (LPG) pool fires. J. Loss Prev. Process Ind. 2019, 61, 13.

3. Li, Y.; Xiao, J.; Zhang, H.; Breitung, W.; Travis, J.; Kuznetsov, M.; Jordan, T. Numerical analysis of hydrogen release, dispersion and combustion in a tunnel with fuel cell vehicles using all-speed CFD code GASFLOW-MPI. Int. J. Hydrog. Energy 2020. [CrossRef]

4. Majder-Lopatka, M.; Wesierski, T.; Dmochowska, A.; Salamonowicz, Z.; Polanczyk, A. The influence of hydrogen on the indications of the electrochemical carbon monoxide sensors. Sustainability 2020, 12, 14. [CrossRef]

5. Pontiggia, M.; Landucci, G.; Busini, V.; Derudi, M.; Alba, M.; Scaioni, M.; Bonvicini, S.; Cozzani, V.; Rota, R. CFD model simulation of LPG dispersion in urban areas. Atmos. Environ. 2011, 45, 11. [CrossRef]

6. Polanczyk, A.; Wawrzyniak, P.; Zbicinski, I. CFD analysis of dust explosion relief system in the counter-current industrial spray drying tower. Dry. Technol. 2013, 31, 10. [CrossRef]

7. Polanczyk, A.; Majder-Lopatka, M.; Dmochowska, A.; Salamonowicz, Z. Analysis of combustion process of protective coating paints. Sustainability 2020, 12, 8. [CrossRef]

8. Pontiggia, M.; Derudi, M.; Busini, V.; Rota, R. Hazardous gas dispersion: A CFD model accounting for atmospheric stability classes. J. Hazard. Mater. 2009, 171, 9. [CrossRef]

9. Hanna, S.; Chang, J.; Strimaitis, D. Hazardous gas model evaluation with field observations. Atmos. Environment. Part A. Gen. Top. 1993, 27, 21. [CrossRef]

10. Markiewicz, M. A review of models for the atmospheric dispersion of heavy gases. Part II. model quality evaluation. Ecol. Chem. Eng. S 2013, 20, 20. [CrossRef]

11. Seibert, P.; Beyrich, F.; Gryning, S.; Joffre, S.; Rasmussen, A.; Philippe, T. Review and intercomparison of operational methods for the determination of the mixing height. Atmos. Environ. 2000, 34, 27. [CrossRef]

12. Agranat, V.; Tchouvelev, A.V.; Cheng, Z.; Zhubrin, S.V. CFD Modeling of Gas Release and Dispersion: Prediction of Flammable Gas Clouds. Adv. Combust. Aerothermal Technol. 2007. [CrossRef]

13. Wawrzyniak, P.; Podyma, M.; Zbicinski, I.; Bartczak, Z.; Polanczyk, A.; Rabaeva, J. Model of Heat and Mass Transfer in an Industrial CounterCurrent Spray-Drying Tower. Dry. Technol. 2012, 30, 9.

14. Wang, K.; Liu, Z.; Qian, X.; Huang, P. Long-term consequence and vulnerability assessment of thermal radiation hazard from LNG explosive fireball in open space based on full-scale experiment and PHAST. J. Loss Prev. Process Ind. 2017, 46, 10. [CrossRef]

15. Thoman, D.C.; O'Kula, K.R.; Laul, J.C.; Davis, M.W.; Knecht, K.D. Comparison of ALOHA and EPIcode for Safety Analysis Applications. J. Chem. Health Saf. 2006, 13, 14. [CrossRef]

16. Joshi, P.; Bikkina, P.; Wang, Q. Consequence analysis of accidental release of supercritical carbon dioxide from high pressure pipelines. Int. J. Greenh. Gas Control 2016, 55, 11. [CrossRef]

17. Wawrzyniak, P.; Polanczyk, A.; Zbicinski, I.; Jaskulski, M.; Podyma, M.; Rabaeva, J. Modeling of Dust Explosion in the Industrial Spray Dryer. Dry. Technol. 2012, 30, 10. [CrossRef]

18. Salamonowicz, Z.; Kotowski, M.; Polka, M.; Barnat, W. Numerical simulation of dust explosion in the spherical 201 vessel. Bull. Pol. Acad. Sci. Tech. Sci. 2015, 63, 5. [CrossRef]

19. Chang, J.; Hanna, S. Air quality model performance evaluation. Meteorol. Atmos. Phys. 2004, 87, 30. [CrossRef]

20. Lawrence, M. The Relationship between Relative Humidity and the Dewpoint Temperature in Moist Air: A Simple Conversion and Applications. Bull. Am. Meteorol. Soc. 2005, 86, 10. [CrossRef]

21. Pope, S.B. Turbulent Flows; Cambridge University Press: Cambridge, UK, 2000.

22. Takashi, S.; Saburo, Y.; Yohe, i.O.; Taku, H. Flame stability and emission characteristics of propane-fueled flat-flame miniature combustor for ultra-micro gas turbines. Combust. Flame 2013, 160, 10.

23. Polanczyk, A.; Salamonowicz, Z.; Majder-Lopatka, M.; Dmochowska, A.; Jarosz, W.; Matuszkiewicz, R.; Makowski, R. 3D Simulation of Chlorine Dispersion in Rrural Area. Annu. Set Environ. Prot. 2018, 20, 1035-1048.

24. Polanczyk, A.; Salamonowicz, Z. Computational modeling of gas mixture dispersion in a dynamic setup-2d and $3 \mathrm{~d}$ numerical approach. E3s Web Conf. 2018, 44, 8. [CrossRef]

25. Ganta, S.E.; Narasimhamurthyb, V.D.; Skjoldb, T.; Jamoisc, D.; Proust, C. Evaluation of multi-phase atmospheric dispersion models for application to Carbon Capture and Storage. J. Loss Prev. Process Ind. 2014, 32, 23. [CrossRef]

26. Zieminska-Stolarska, A.; Polanczyk, A.; Zbicinski, I. 3-D CFD simulations of hydrodynamics in the Sulejow dam reservoir. J. Hydrol. Hydromech. 2015, 63, 8. [CrossRef]

27. Pontiggiaa, M.; Derudi, M.; Alba, M.; Scaioni, M.; Rota, R. Hazardous gas releases in urban areas: Assessment of consequences through CFD modelling. J. Hazard. Mater. 2010, 176, 8. [CrossRef] [PubMed]

28. Ehsan, H.; Hamidreza, S.; Stanko, D.; Michael, F.; Kaamran, R. Assessing the potential of fuel cell-powered and battery-powered forklifts for reducing GHG emissions using clean surplus power; a game theory approach. Int. J. Hydrog. Energy 2020, 45, 13. 
29. Scarponi, G.E.; Landucci, G.; Birk, A.M.; Cozzani, V. An innovative three-dimensional approach for the simulation of pressure vessels exposed to fire. J. Loss Prev. Process Ind. 2019, 61, 160-173. [CrossRef]

30. Bi, M.-s.; Ren, J.-j.; Zhao, B.; Che, W. Effect of fire engulfment on thermal response of LPG tanks. J. Hazard. Mater. 2011, 192, 6. [CrossRef]

31. Hwang, J.-W.; Yoon, D.-Y.; Choi, K.-H.; Kim, Y.; Kim, L.H. 3D CFD analysis of the hydrogen releases and dispersion around storage facilities. Korean J. Chem. Eng. 2008, 25, 6. [CrossRef]

32. Rigas, F.; Sklavounos, S. Risk and consequence analyses of hazardous chemicals in marshalling yards and warehouses at Ikonio/Piraeus harbour, Greece. J. Loss Prev. Process Ind. 2002, 15, 14. [CrossRef]

33. Krauze, A. The application of CFD software in the explosive hazardous area classification. MATEC Web Conf. 2018, 247, 8. [CrossRef] 